\title{
Low body condition predisposes cattle to lameness: An 8-year study of one dairy herd
}

\author{
L. V. Randall, ${ }^{* 1}$ M. J. Green, ${ }^{*}$ M. G. G. Chagunda, † C. Mason,† S. C. Archer, ${ }^{*}$ L. E. Green, $\ddagger$ and J. N. Huxley* \\ ${ }^{*}$ School of Veterinary Medicine and Science, University of Nottingham, Sutton Bonington Campus, Sutton Bonington, Leicestershire, LE12 5RD, \\ United Kingdom \\ †Scotland's Rural College, Kings Buildings, West Mains Road, Edinburgh, EH9 3JG, United Kingdom \\ ¥School of Life Sciences, University of Warwick, Coventry CV4 7AL, United Kingdom
}

\begin{abstract}
Lameness in dairy cows is a multifactorial and progressive disease with complex interactions between risk factors contributing to its occurrence. Detailed records were obtained from one United Kingdom dairy herd over an 8-yr period. Weekly locomotion scores were used to classify cows as not lame (score 1 to 2), mildly lame (score 3 ) and severely lame (score 4 to 5 ). These outcomes were used to investigate the hypothesis that low body condition score (BCS) is associated with an increased risk of lameness in dairy cows. Mixed effect multinomial logistic regression models were used to investigate the association between prior BCS and repeat lameness events during the longitudinal period of the study. Discrete time survival models were used to explore the relationship between prior BCS and first lifetime lameness events. In total, 79,565 cow weeks at risk were obtained for 724 cows. The number of lameness events was 17,114 , of which 8,799 were categorized as mildly lame and 8,315 as severely lame. The median BCS was 2.25 (range, 0.75 to 4.25 ) and the mean body weight (BW) and age at first calving were $619.5 \mathrm{~kg}$ (range, 355.6 to $956.4 \mathrm{~kg}$ ) and $25.8 \mathrm{mo}$ (range, 20.5 to $37.8 \mathrm{mo}$ ), respectively. Subsets of the data were used in the discrete time survival models: 333 mild and 211 severe first lifetime lameness events in heifers (first lactation cows), and 81 mild and 49 severe first lifetime lameness events in cows second lactation or greater. Low BCS 3 wk before a repeated lameness event was associated with a significantly increased risk of lameness. Cows with BCS $<2$ were at greatest risk of mild or severe lameness, and an increased BCS above 2 was associated with a reduced risk of mild or severe lameness. Low BCS 16 or 8 wk before a first mild or severe lifetime lameness event, respectively, also had a positive association with risk of lameness in cows second lactation or greater. This provides evidence to support
\end{abstract}

Received September 16, 2014.

Accepted February 9, 2015

${ }^{1}$ Corresponding author: svxlr@nottingham.ac.uk targeting management toward maintaining $\mathrm{BCS}$ to minimize the risk of lameness. Low BW (independent of BCS) and increased age at first calving above 24 mo were also associated with increased long-term risk of repeated lameness events. Overall, the model explained 62 and $60 \%$ of the variability for mild and severe lameness, respectively, highlighting the importance of these variables as risk factors and hence where management could be targeted to significantly affect reducing the risk of lameness.

Key words: dairy cattle, lameness, body condition score, body weight, age at first calving

\section{INTRODUCTION}

Lameness is considered by the dairy industry to be one of the most significant current challenges (Huxley, 2012). Extensive effects on herd performance are reported, including milk yield loss (Green et al., 2002; Amory et al., 2008), increased culling (Booth et al., 2004), and impaired reproductive performance (Garbarino et al., 2004). The significance of these effects extends beyond the financial implications. The importance of sustainable food production and welfare, and the potential effects of lameness on these, are increasingly being recognized (Huxley, 2012; Herrero and Thornton, 2013). As a consequence of intensification of dairy production, an associated risk of lameness has increased (Huxley, 2012). The prevalence of lameness in intensively managed dairy herds is approximately $20 \%$ (Cook, 2003; Espejo et al., 2006). In the United Kingdom, one estimate of incidence was approximately 50 cases/100 cows per yr (Archer et al., 2010a), although Whay et al. (2003) highlighted the poor correlation between incidence rates and records of treatments for lameness on farm, suggesting that the true incidence of lameness in the UK national herd is likely to be higher.

Several cow level factors have been associated with an increased incidence of lameness. Higher yielding cows are more likely to become lame while also still producing more milk over a lactation than cows that are never lame, even though lameness can result in 305- 
$\mathrm{d}$ yield losses in the region of $350 \mathrm{~kg}$ (Green et al., 2002; Bicalho et al., 2008; Archer et al., 2010b). Cows with low $\mathrm{BCS} \leq 2$ (on a scale 0 to 5 ) are more likely to be treated for lameness in the 2 or $>2$ to 4 mo following such a score (Green et al., 2014). This finding supports the hypothesis that low BCS is associated with claw horn lesions, possibly due to reduced digital cushion thickness, which has been correlated with low BCS (Bicalho et al., 2009). In the current paper, we use a longitudinal study to explore the hypothesis that cows in low body condition are at increased risk of lameness measured as repeat locomotion scores, to better understand and support decision making in the control of lameness.

\section{MATERIALS AND METHODS}

\section{Study Herd}

Records were obtained for the 8-yr period from 2003 to 2011, from a total of 724 cows managed on the Langhill herd held at the Scotland's Rural College's Crichton Royal research farm in Dumfries, Scotland. The herd consisted of Holstein Friesians managed on a long-term $2 \times 2$ factorial genetic and feeding system study, select and control genetic lines (as described by Pryce et al., 1999), managed as one herd of approximately 200 cows, divided equally into low-forage $(\mathbf{L F})$ and high-forage (HF) groups. Chagunda et al. (2009) describe the diets and management systems in detail. Briefly, LF cows were continuously housed and fed a complete diet containing between 45 and $50 \%$ forage in the DM. The $\mathrm{HF}$ cows were grazed during summer months provided sufficient grass was available and then housed during winter months (typically November to March) and fed a complete diet containing 70 to $75 \%$ forage in the DM. The forage component of the diet included grass silage, maize silage, and whole crop wheat. Concentrates were included in the LF and HF diets at approximately 1,200 and $3,000 \mathrm{~kg}$ per cow per year, respectively. Table 1 presents a summary of the target composition of the diets offered to the 2 groups. Target yields for $\mathrm{LF}$ and HF cows were 13,000 and 7,500 kg per cow per year, respectively. The herd was all-year-round calving and milked 3 times daily through a 14/14 herringbone parlor. All replacement dairy animals were bred and reared on the unit. Target age at first calving was 24 mo, with first service scheduled at approximately 350 $\mathrm{kg}$ of BW and 15 mo of age. Housing was the same for cows in LF and HF groups: cubicles with mattresses installed in 2004 (mats were present before this) and sawdust bedding. Stocking density never exceeded one cow per cubicle and regularly ran at less than this. Passageways were automatically scraped every $2 \mathrm{~h}$. Footbathing was carried out at 3 consecutive milkings per week for lactating cows, monthly for young stock, and weekly for dry cows using 5\% copper sulfate solution. Locomotion scores and BCS were collected weekly by experienced, trained assessors following standard protocols. Assessors alternated every week to reduce the effect of operator bias, and regular training was carried out with the same veterinarian during the whole study period. Locomotion scores (LS) were measured using a 1 to 5 scale according to Manson and Leaver (1988). Cows considered lame (LS 4 or 5 on a single occasion or 2 successive assessments of LS 3) were examined and treated by a veterinarian on a weekly basis before 2006 and every 2 wk after this time. A professional foot trimmer attended twice a year to trim the whole herd (all hind feet and front feet if they were considered overgrown). Acutely lame cows were treated by trained farm staff within $24 \mathrm{~h}$ of observation. Body condition score was measured using a 0 to 5 categorical scale with increments of 0.25 (Mulvany, 1977). Body weights were recorded using an automatic weighing system after milking 3 times daily. All health, production, and management data were recorded in a database.

\section{Statistical Analysis}

General Approach to Modeling. Data were obtained for the 8-yr period September 1, 2003, to Au-

Table 1. Target composition for the diets offered to low forage and high forage groups of the Crichton Royal research herd for the period 2003 to 2011

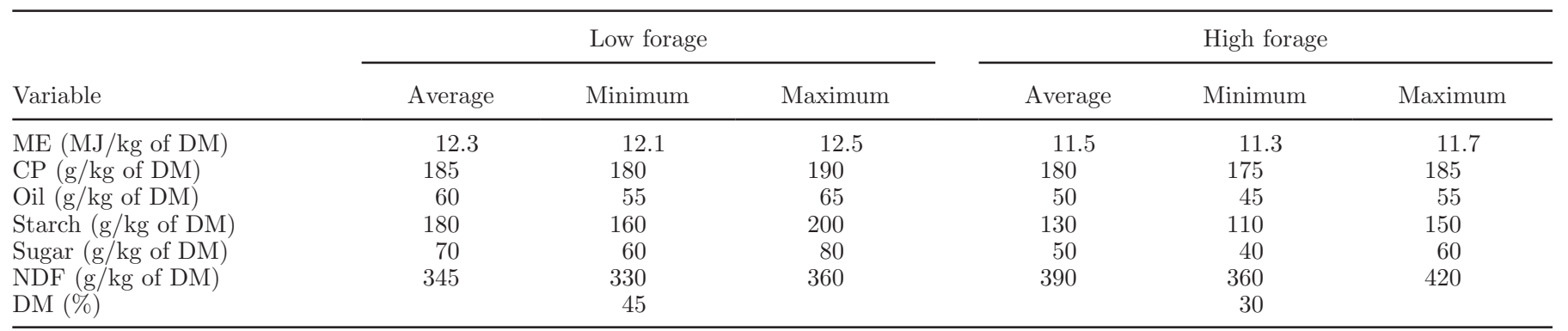


gust 31, 2011, and structured at the cow week level. Data handling included identification and removal of anomalous or unusual data, duplicate records, and constructing outcome and explanatory variable categories. Locomotion score was the outcome variable and categorized as not lame (LS 1 or 2), mildly lame (LS 3), or severely lame (LS 4 or 5). Categories for the explanatory variables were explored and defined in terms of similarity in risk and number of data points within each category. Categorical explanatory variables tested included categories for parity, feed-genetic group (low forage-control: LF-C; low forage-select: LF-S; high forage-control: HF-C; high forage-select: HF-S; dry-control: D-C; dry-select: D-S; other-control: O-C; other-select: O-S), milk yield, age at first calving, BCS at calving, BCS change 0 to 4 wk postcalving, BW, and BCS. Weeks in milk (WIM) was tested as an explanatory variable with polynomials up to the power 5 . Week of the study was included as an explanatory variable with categories or polynomials to account for changes in background risk of lameness over time. Categories for milk yield, BW, and BCS were lagged by 2, 3, 4, 8, 12 , and $16 \mathrm{wk}$ to explore their longitudinal association with lameness outcomes. Locomotion score and BCS assessor was included as an explanatory variable (locomotion score recorder; 1 to 5 ) to control for possible inter-observer variability.

Mixed-effect hierarchical models were used to explore the relationship between explanatory variables and lameness outcomes. The models were constructed in MLWiN 2.28 (Rabash et al., 2009), and initially model parameters were estimated by the iterative generalized least square procedure (Goldstein, 2003). Lagged yield, BW, and BCS were explored systematically to identify the time periods that had a significant effect on the response variable. Where lagged weeks were correlated, those with the largest effect size were left in the model. Final parameter estimates for each model investigated were made using Markov Chain Monte Carlo to reduce biased estimates (Rabash et al., 2009), using procedures as previously described by Green et al. (2004). In brief, a minimum burn-in of 1,000 iterations was used during which model convergence occurred, with parameter estimates being based on a further 50,000 iterations. Chain mixing and stability were evaluated visually. Explanatory variables remained if the $95 \%$ credible interval of the odds ratio did not include 1 , and as such these terms were considered significant. Posterior predictions were used to assess model fit by visual comparison with observed data (Gelman et al., 1996) and the Hosmer-Lemeshow test statistic (Hosmer and Lemeshow, 1989). Posterior predictions were also used to compare the predicted cow level lameness (total number of events) to the observed data.
Modeling Was Conducted in 2 Stages: Multinomial Model for Repeated Lameness Events (Model 1). A mixed effect multinomial logistic regression model (Goldstein, 2003) with unordered categories was used to analyze the data as a frailty model, where each cow could have repeated lameness events over time. Cow was included as a random effect and time since the last lameness event as a fixed effect. The model took the form

$$
\begin{aligned}
\text { lame }_{\mathrm{ij}} \sim & \text { multinomial (probability } \left.=\pi_{\mathrm{ij}}\right) \\
\log \left(\pi_{1 \mathrm{ij}} / \pi_{0 \mathrm{ij}}\right) & =\alpha+\boldsymbol{\beta}_{1} \mathrm{wk}_{\mathrm{ij}}+\boldsymbol{\beta}_{2} \mathrm{wk}_{\mathrm{ij}}^{2}+\boldsymbol{\beta}_{3} \mathrm{wk}^{3}{ }_{\mathrm{ij}} \\
& +\boldsymbol{\beta}_{4} \mathbf{X}_{\mathrm{ij}}+\boldsymbol{\beta}_{5} \mathbf{X}_{\mathrm{j}}+\mathrm{v}_{0 \mathrm{j}} \\
\log \left(\pi_{2 \mathrm{ij}} / \pi_{0 \mathrm{ij}}\right) & =\alpha+\boldsymbol{\beta}_{1} \mathrm{wk}_{\mathrm{ij}}+\boldsymbol{\beta}_{2} \mathrm{wk}_{\mathrm{ij}}^{2}+\boldsymbol{\beta}_{3} \mathrm{wk}_{\mathrm{ij}}^{3} \\
& +\boldsymbol{\beta}_{4} \mathbf{X}_{\mathrm{ij}}+\boldsymbol{\beta}_{5} \mathbf{X}_{\mathrm{j}}+\mathrm{v}_{1 \mathrm{j}} \\
& {\left[\begin{array}{c}
\mathrm{v}_{0 \mathrm{j}} \\
\mathrm{v}_{1 \mathrm{j}}
\end{array}\right] \sim N\left(0, \boldsymbol{\Omega}_{\mathrm{v}}\right), }
\end{aligned}
$$

where subscripts $i$ and $j$ denote the ith observation of the jth cow, respectively. $\pi_{1 \mathrm{ij}}=$ probability of mildly lame outcome for the ith observation of the jth cow, $\pi_{2 \mathrm{ij}}=$ probability of severely lame outcome for the ith observation of the jth cow. $\alpha=$ intercept value, $w_{\mathrm{ij}}$ = week of the study for the ith observation of the jth cow, $\boldsymbol{\beta}_{1}$ to $\boldsymbol{\beta}_{3}=$ vector of coefficients for $\mathrm{wk}_{\mathrm{ij}}, \mathbf{X}_{\mathrm{ij}}=$ the vector of covariates associated with each observation, $\boldsymbol{\beta}_{4}=$ vector of coefficients for $\mathbf{X}_{\mathrm{ij}}, \mathbf{X}_{\mathrm{j}}=$ vector of covariates associated with each cow, $\boldsymbol{\beta}_{5}=$ the coefficients for covariates $\mathbf{X}_{j} ; v_{0 j}$ and $v_{1 j}$ were random effects to account for residual variation between cows (assumed to have a multivariate normal distribution of mean $=$ 0 and variance-covariance matrix $=\Omega_{\mathrm{v}}$ ). Explanatory variables tested and the approaches to model building and fit are described above. Briefly, lagged (2 to $16 \mathrm{wk}$ previously) BCS categories tested were $<2,2,2.25,2.5$, $2.75,3$, and $>3$, and lagged (2 to 16 wk previously) BW categories tested were $<550,550$ to 700 , and $>700 \mathrm{~kg}$. The Pearson correlation coefficient was used to assess the amount of cow level variability explained by the model prediction (Dohoo et al., 2003).

Binomial Models for Survival to First Lifetime Lameness Event (Models 2a, 2b, 3a, and 3b). To allow previous BCS to be investigated without the confounding effect of a previous lame event, discrete time survival models were used with the outcome survival to a first lifetime lameness event for each cow.

Two different subsets of these data were used: 1) first lifetime lameness events in heifers (first lactation; 
models $2 \mathrm{a}$ and $2 \mathrm{~b}$; first mild lameness event and severe lameness event, respectively); 2) first lifetime lameness event in cows in their second lactation or greater (models 3a and 3b; first mild lameness event and severe lameness event, respectively). For each subset of data, 2 separate models were constructed with lameness outcomes categorized as mildly lame (LS 3), and severely lame (LS 4 or 5 ). The baseline for all models was cows that had not been lame. Once a cow had been recorded lame all subsequent records were removed and therefore only events before a first lameness case were modeled. Models took the following form:

$$
\begin{gathered}
\text { lame_category }_{\mathrm{ij}} \sim \text { Bernoulli }_{\left(\text {probability }=\pi_{\mathrm{ij}}\right)} \\
\operatorname{logit}\left(\pi_{\mathrm{ij}}\right)=\alpha+\boldsymbol{\beta}_{1} \mathrm{wk}_{\mathrm{ij}}+\boldsymbol{\beta}_{2} \mathbf{X}_{\mathrm{ij}}+\boldsymbol{\beta}_{3} \mathbf{X}_{\mathrm{j}}+\mathrm{u}_{\mathrm{j}} \\
\mathrm{u}_{\mathrm{j}} \sim \mathrm{N}\left(0, \sigma_{\mathrm{v}}^{2}\right)
\end{gathered}
$$

where subscripts $i$ and $j$ denote the ith observation of the jth cow, $\pi_{\mathrm{ij}}=$ probability of a lame outcome for the ith observation of the jth cow, $\alpha=$ intercept value, $w_{\mathrm{ij}}$ $=$ categorical variable to represent week of the study for the ith observation of the jth cow, $\boldsymbol{\beta}_{1}=$ vector of coefficients for $\mathrm{wk}_{\mathrm{ij}}, \mathbf{X}_{\mathrm{ij}}=$ the vector of covariates associated with each observation, $\boldsymbol{\beta}_{2}=$ vector of coefficients for $\mathbf{X}_{\mathrm{ij}}, \mathbf{X}_{\mathrm{j}}=$ vector of covariates associated with each cow, $\boldsymbol{\beta}_{3}=$ the coefficients for covariates $\mathbf{X}_{\mathrm{j}}$; $\mathrm{u}_{\mathrm{j}}=$ random effect to account for residual variation between cows (assumed to be normally distributed with mean $=$ 0 and variance $=\sigma^{2}{ }_{\mathrm{v}}$ ). Explanatory variables tested and the approaches to model building and fit are described above. Briefly, lagged (2 to $16 \mathrm{wk}$ previously) BCS categories tested were $<2,2,2.25,2.5, \geq 2.75$ (models $2 \mathrm{a}$ and $2 \mathrm{~b}$ ) and $<2,2,2.25$, and $\geq 2.5$ (models $3 \mathrm{a}$ and $3 \mathrm{~b}$ ). Lagged ( 2 wk to 16 wk previously) BW categories tested were $<505,505$ to $560,>560 \mathrm{~kg}$ (models $2 \mathrm{a}$ and
$2 \mathrm{~b}$ ) and $<600,600$ to 650 , and $>650 \mathrm{~kg}$ (models $3 \mathrm{a}$ and $3 \mathrm{~b}$, respectively).

\section{RESULTS}

\section{Multinomial Model for Repeated Lameness Events (Model 1)}

The data set included a total of 79,565 cow weeks at risk. The number of lameness events was $17,114,8,799$ of which were mildly lame (LS 3) and 8,315 of which were severely lame (LS 4 or 5). The numbers of recordings for BCS and weekly average BW, respectively, were 79,543 and 62,643 . The median BCS was 2.25 (range, 0.75 to 4.25$)$ and mean $( \pm \mathrm{SD}) \mathrm{BW}$ was $619.5( \pm 80.5)$ $\mathrm{kg}$ (range, 355.6 to $956.4 \mathrm{~kg}$ ). Mean age at first calving for the herd over the 8-yr period was 25.8 mo (range, 20.5 to $37.8 \mathrm{mo}$ ). The majority of cows were parity 1 to 3 during the study period; mean parity over the study period was 2.1 , with $38 \%$ parity $1,28 \%$ parity $2,21 \%$ parity 3 , and $13 \%$ parity $4+$ cows. The proportion of cows with locomotion score 3 decreased with increasing parity, and the proportion of cows with locomotion score 4 and 5 increased with increasing parity. The proportion of lame (mild and severe) observations in each lagged BCS category (3 wk through 16 wk) had a trend of decreasing percentage of lame events from BCS $<2$ to BCS $>3$, with BCS 2.5 having the lowest percentage (Table 2 ).

Tables 3 and 4 show the results from model 1. Lagged explanatory variables for BCS and BW were correlated from 2 through 16 wk. A significantly increased risk of mild or severe lameness was observed in cows with BCS $<2$ three weeks before the lameness event compared with other BCS categories, and a pattern of decreasing risk of lameness was observed with increasing BCS, as illustrated in Figure 1. Effect sizes for all BCS scores were larger for severely compared with mildly lame

Table 2. Proportion of lame (mild and severe) observations in each lagged BCS category (3, 8, 12, and 16 wk previously) in the Crichton Royal research herd for the study period 2003 to 2011

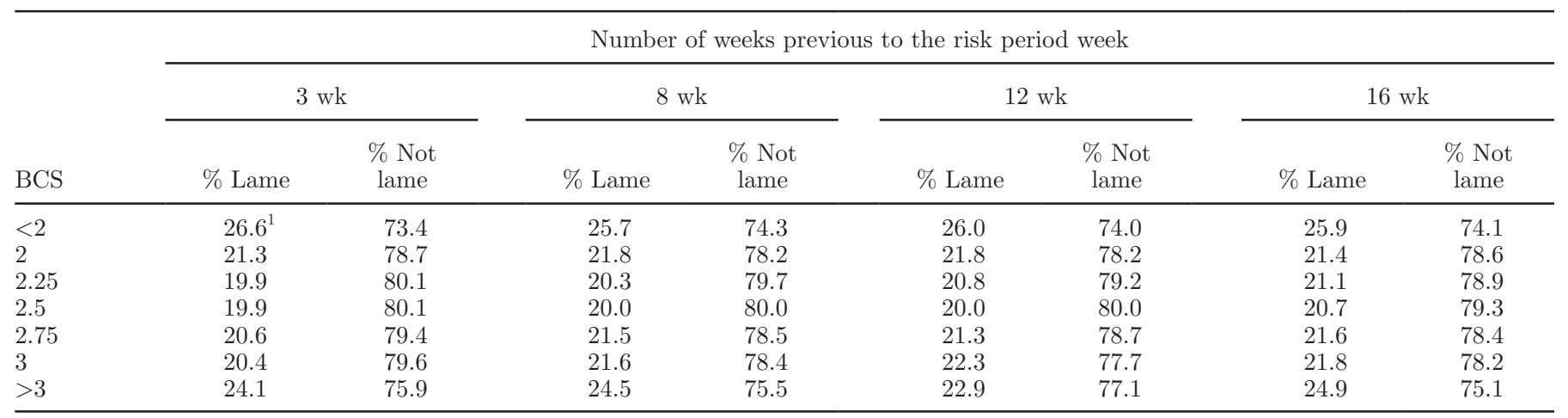

${ }^{1}$ For example, $26.6 \%$ of all the observations that had a BCS of $<2$ three weeks previously were recorded as lame. 
cows. Low BW cows were at significantly increased risk of mild or severe repeated lameness events compared with cows in heavier BW categories. Compared with the baseline category of $<550 \mathrm{~kg}$, cows in the 550 to $700 \mathrm{~kg}$ category were less likely to become mildly lame [odds ratio $(\mathbf{O R})(95 \%$ credible interval $)=0.88(0.81$ to 0.97$)$ ] and severely lame [OR (95\% credible interval) $=0.82(0.74$ to 0.92$)]$. The risk of lameness decreased as BW increased (Figure 1).

Age at first calving $<24$ mo was associated with the least risk of subsequently becoming being mildly lame or severely lame $[\mathrm{OR}(95 \%$ credible interval $)=0.77$
(0.64 to 0.91 ) and 0.75 (0.56 to 0.99 ), respectively] when compared with a baseline of 24 to 27 mo. Cows with age at first calving $>33$ mo were at greatest risk of subsequently being mildly lame or severely lame [OR $(95 \%$ credible interval $)=2.14$ (1.21 to 3.80$)$ and 2.87 (1.16 to 7.12), respectively], as seen in Figure 1.

Cows losing body condition in the first 4 wk after calving were at significantly higher risk of future lameness $[\mathrm{OR}(95 \%$ credible interval $)=1.21$ (1.03 to 1.42$)$ for severely lame cows] compared with a baseline of no change in BCS. This association was significant for severely lame cows only. Cows that had previously been

Table 3. Model 1: final multinomial model of risk of repeated lameness events in the Crichton Royal research herd 2003 to 2011 with outcomes mildly lame and severely lame ${ }^{1,2}$

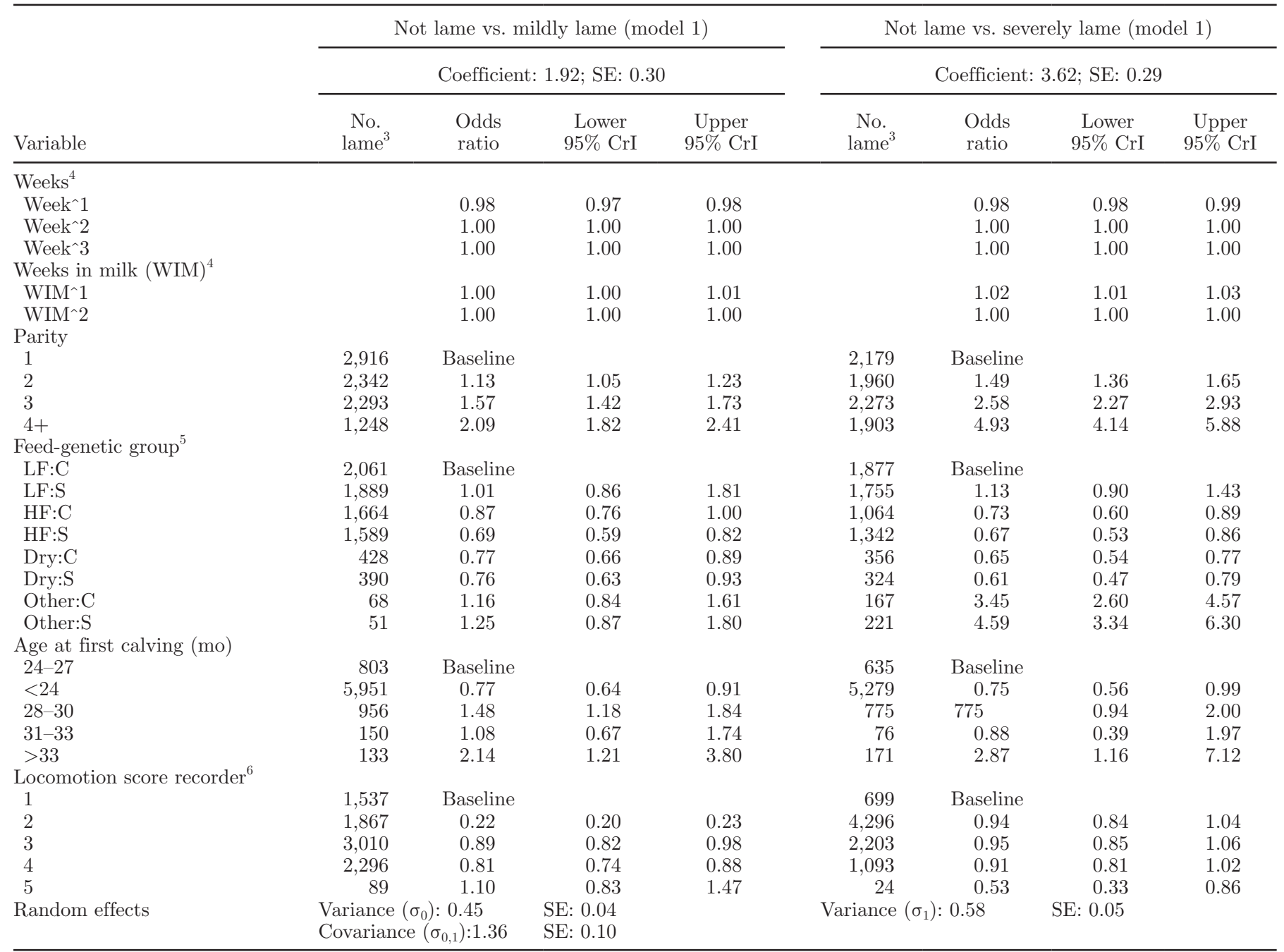

\footnotetext{
${ }^{1}$ Table 3 refers to the single multinomial model (model 1) comparing two outcomes (mildly lame and severely lame). CrI $=$ credible interval.

${ }^{2}$ Some nonsignificant results are shown as they represent part of the multinomial model.

${ }^{3}$ Number of lameness events in each category.

${ }^{4}$ Explanatory variables weeks (week of the study) and WIM included as a polynomial to power $3(\wedge 3)$ and $2(\wedge 2)$.

${ }^{5}$ Feed-genetic groups include low forage (LF), high forage (HF), control (C), and select (S). Dry refers to dry cows, and other refers to all other management groups outside of LF, HF, and dry.

${ }^{6}$ Locomotion score recorder $=$ individual locomotion score/BCS observer identification.
} 
Table 4. Model 1 continued: final multinomial model of risk of repeated lameness events in the Crichton Royal research herd 2003 to 2011 with outcomes mildly lame and severely lame $e^{1,2}$

\begin{tabular}{|c|c|c|c|c|c|c|c|c|}
\hline Variable & \multicolumn{4}{|c|}{ Not lame vs. mildly lame (model 1) } & \multicolumn{4}{|c|}{ Not lame vs. severely lame (model 1) } \\
\hline \multicolumn{9}{|c|}{ Previous lameness (LS 3,4, or 5 ) } \\
\hline None & & Baseline & & & & Baseline & & \\
\hline 9 to $12 \mathrm{wk}$ & 5,089 & 1.25 & 1.17 & 1.33 & 5,243 & 1.28 & 1.19 & 1.38 \\
\hline 13 to $16 \mathrm{wk}$ & 4,846 & 1.24 & 1.16 & 1.32 & 4,819 & 0.99 & 0.92 & 1.06 \\
\hline$>16 \mathrm{wk}$ & 258 & 1.00 & 0.72 & 1.39 & 389 & 1.35 & 1.00 & 1.82 \\
\hline \multicolumn{9}{|c|}{ BCS $3 \mathrm{wk}$ previously } \\
\hline$<2$ & 1,963 & Baseline & & & 1,965 & Baseline & & \\
\hline 2 & 2,086 & 0.91 & 0.84 & 0.98 & 1,884 & 0.80 & 0.73 & 0.87 \\
\hline 2.25 & 2,130 & 0.90 & 0.82 & 0.98 & 1,994 & 0.73 & 0.67 & 0.80 \\
\hline$<550$ & 1,491 & Baseline & & & 1,119 & Baseline & & \\
\hline 550 to 700 & 4,156 & 0.88 & 0.81 & 0.97 & 4,206 & 0.82 & 0.74 & 0.92 \\
\hline$>700$ & 1,159 & 0.84 & 0.74 & 0.97 & 1,232 & 0.72 & 0.62 & 0.84 \\
\hline \multicolumn{9}{|c|}{ Milk yield 3 wk previously $(\mathrm{kg})$} \\
\hline$<12$ & 105 & Baseline & & & 109 & Baseline & & \\
\hline 12 to 24 & 2,076 & 0.87 & 0.68 & $1.11^{*}$ & 1,884 & 0.82 & 0.63 & 1.07 \\
\hline 25 to 37 & 3,536 & 0.81 & 0.63 & $1.05^{*}$ & 3,258 & 0.68 & 0.52 & 0.89 \\
\hline 38 to 50 & 1,312 & 0.81 & 0.63 & $1.06^{*}$ & 1,239 & 0.62 & 0.47 & 0.83 \\
\hline \multirow{2}{*}{\multicolumn{9}{|c|}{ Milk yield 16 wk previously $(\mathrm{kg})$}} \\
\hline & & & & & & & & \\
\hline$<12$ & 75 & Baseline & & & 44 & Baseline & & \\
\hline 12 to 24 & 1,784 & 0.95 & 0.72 & $1.26^{*}$ & 1,515 & 1.49 & 1.03 & 2.15 \\
\hline 25 to 37 & 3,324 & 0.98 & 0.75 & $1.30^{*}$ & 3,118 & 1.58 & 1.09 & 2.29 \\
\hline
\end{tabular}

${ }^{1}$ Table 4 refers to the single multinomial model (model 1) comparing two outcomes (mildly lame and severely lame). CrI $=$ credible interval.

${ }^{2}$ Some nonsignificant results are shown because they represent part of the multinomial model (e.g., results marked *).

lame (LS 3 to 5) were at higher risk of being mildly or severely lame. This effect was significant when lameness occurred any time between 1 and 16 wk previously, with the previous 1 to 4 wk having the largest effect [OR $(95 \%$ credible interval $)=2.09$ (1.96 to 2.23$)$ and 3.85 (3.56 to 4.18)]. A previous lameness event $>16 \mathrm{wk}$ previously also increased the risk of severe lameness.

Higher parity cows were at greater risk of lameness compared with parity 1 cows; parity $4+$ OR (95\% credible interval) $=2.09$ (1.82 to 2.41 ) and 4.93 (4.14 to 5.88 ) for mildly and severely lame categories, respectively. With LF:C as the baseline category, grazed cows (HF:S and HF:C) were significantly less likely to be severely lame (OR $(95 \%$ credible interval $)=0.73(0.60$ to 0.89 ) and 0.67 (0.53 to 0.86 ) for HF:C and HF:S cat- egories, respectively). The HF:S cows were significantly less likely to be mildly lame [OR (95\% credible interval) $=0.69(0.59$ to 0.82$)]$. Cows with lower yields $3 \mathrm{wk}$ previously and cows with higher yields 16 wk previously were at significantly greater risk of severe lameness. The Pearson correlation coefficient $\left(\mathrm{r}^{2}\right)$ estimated from model 1 was 0.62 and 0.60 for mildly and severely lame outcomes, respectively. Model fit was good.

\section{Binomial Models for Survival to First Lifetime Lameness Event (Models 2a, 2b, 3a, and 3b)}

Data sets used in the analysis for first lifetime lameness events, models $2 \mathrm{a}$ and 2b, included 4,983 (375) and 3,070 (252) cow weeks at risk (number of cows), respec- 
(a) Model 1; mildly lame

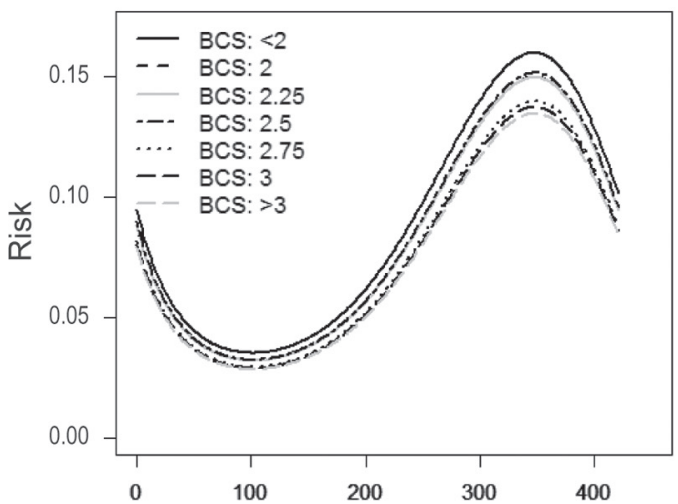

(c) Model 1; mildly lame

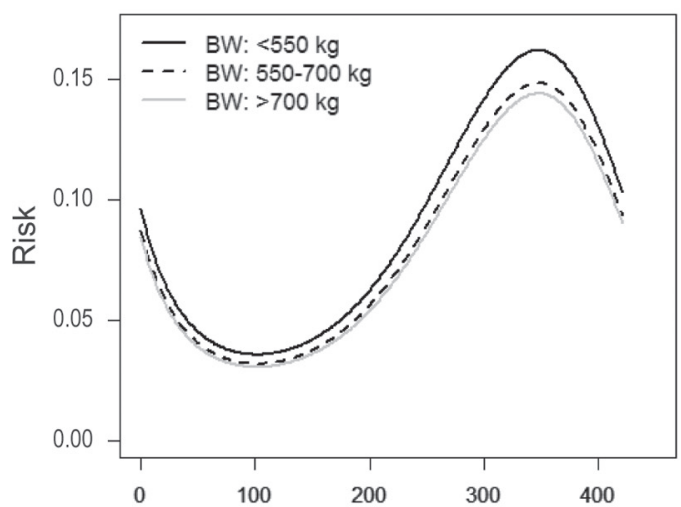

(e) Model 1; mildly lame

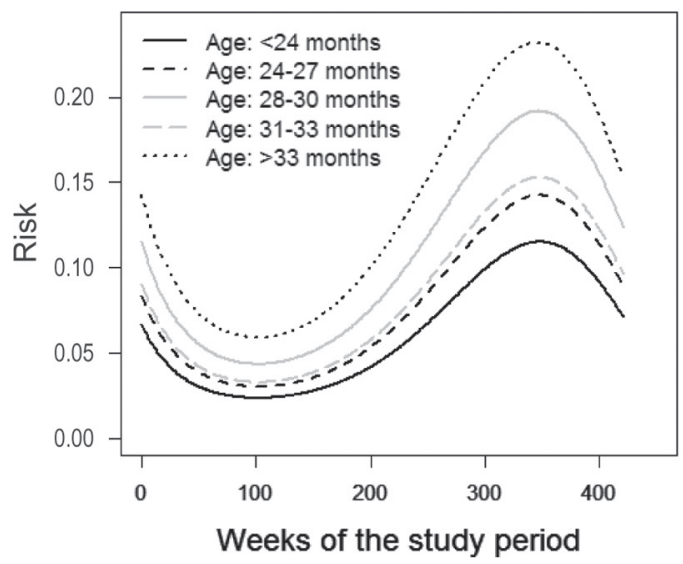

(b) Model 1; severely lame

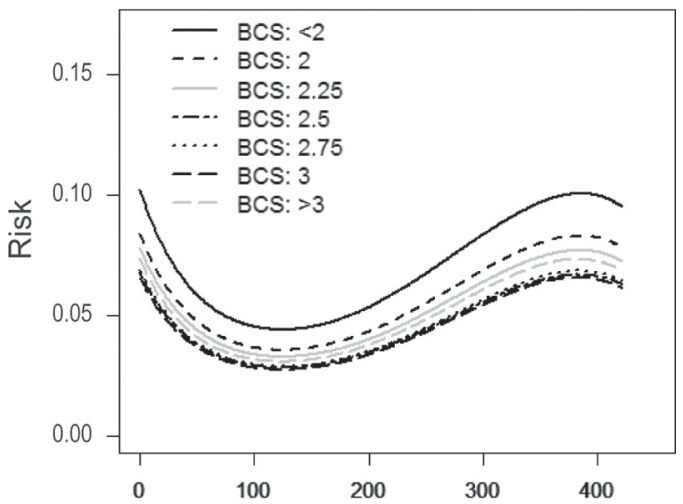

(d) Model 1; severely lame

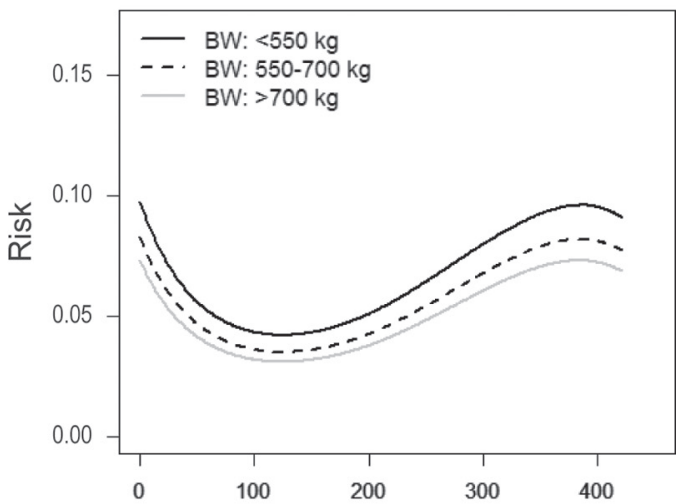

(f) Model 1; severely lame

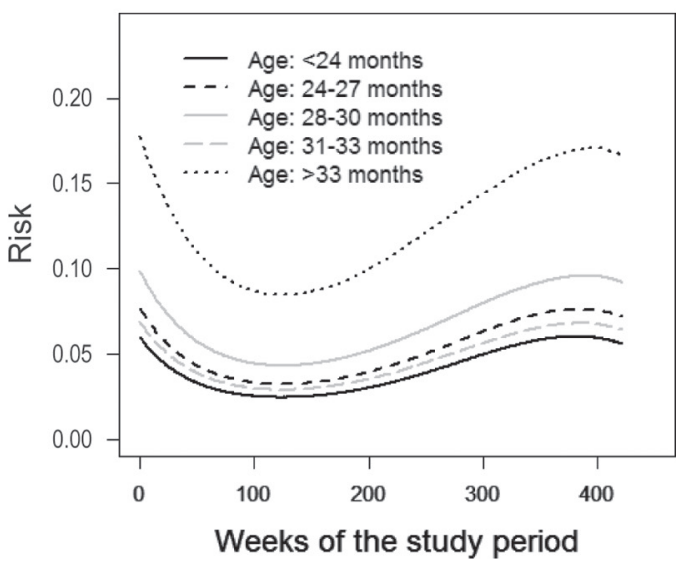

Figure 1. Median predicted risk of lameness from multinomial model parameters (model 1) in the Crichton Royal research herd for the 421 wk of the study period September 1, 2003, to August 31, 2011. (a) Shows the median predicted risk for BCS categories 3 wk previously with the outcome mildly lame and (b) severely lame. (c) Shows the median predicted risk for BW categories 3 wk previously with the outcome mildly lame and (d) severely lame. (e) Shows the median predicted risk for age at first calving categories with the outcome mildly lame and (f) severely lame. 
tively. The number of first lifetime lameness events was 333 with the outcome mildly lame and 211 with the outcome severely lame.

Results from models $2 \mathrm{a}$ and $2 \mathrm{~b}$ are summarized in Table 5. A BCS $\geq 2.752$ wk previous to a first mild lameness event was associated with the lowest risk of lameness compared with the baseline BCS of $<2$ [OR $(95 \%$ credible interval $)=0.37(0.16$ to 0.90$)]$. This association was not significant for severe lameness or with any other of the lagged BCS variables tested for mild lameness. The HF:S cows were at significantly less risk of a first severe lameness event compared with the baseline category of LF:C [OR (95\% credible interval) $=0.06$ (0.01 to 0.63)]. Other variables tested, including BW, BCS at calving, BCS change 0 to 4 wk postcalving, and milk yield, were not significant. Model fit was good.

Data sets used in the analysis for first lifetime lame events in second or greater lactation animals (i.e., excluding parity 1 cows), models $3 \mathrm{a}$ and $3 \mathrm{~b}$, included

Table 5. Models 2a and 2b: final binomial models of risk of first lifetime lameness event in heifers (first lactation) in the Crichton Royal research herd 2003 to 2011 with outcomes mildly lame (model 2a) and severely lame (model 2b)

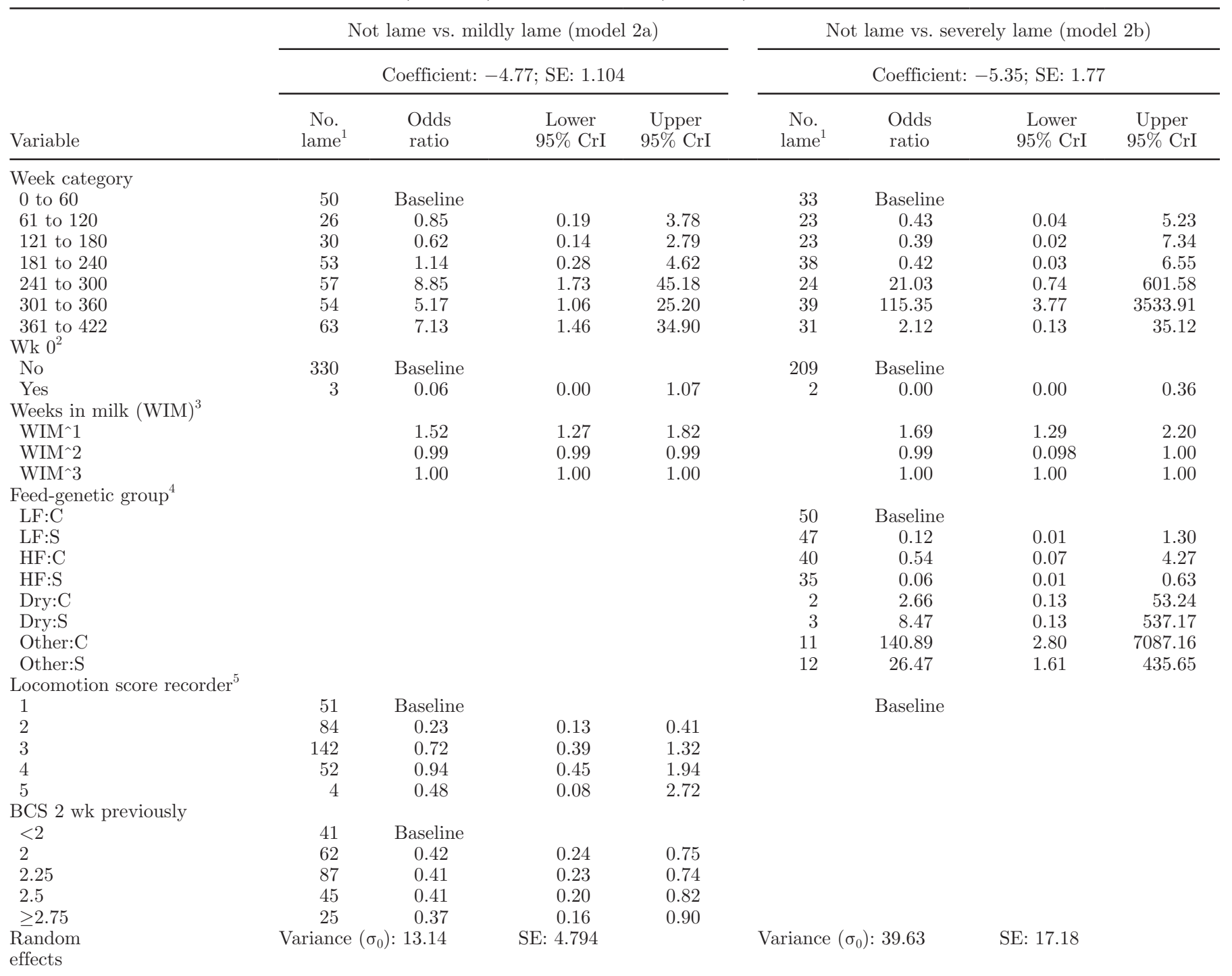

${ }^{1}$ Number of lameness events in each category. $\mathrm{CrI}=$ credible interval.

${ }^{2}$ Explanatory variable as a binary outcome for week $=0$.

${ }^{3}$ Explanatory variable weeks in milk (WIM) included as a polynomial to the power $3(\wedge 3)$.

${ }^{4}$ Feed-genetic groups include low forage (LF), high forage (HF), control (C), and select (S). Dry refers to dry cows and other refers to all other management groups outside of LF, HF, and dry.

${ }^{5}$ Locomotion score recorder $=$ individual locomotion score/BCS observer identification. 
1,961 (91) and 1,503 (59) cow weeks at risk (number of cows), respectively. The number of first lifetime lameness events was 81 with the outcome mildly lame and 49 with the outcome severely lame.

Results from models $3 \mathrm{a}$ and $3 \mathrm{~b}$ are summarized in Table 6. Lagged explanatory variables for BCS were correlated and significantly associated with risk of lameness at 12 and 16 wk previously for first mild lameness event and 8 and 12 wk previously for first severe lameness event. Cows with BCS $\geq 2.516$ wk previous to a mild lameness event were at reduced risk of lameness compared with the baseline (BCS <2) with OR $(95 \%$ credible interval $)=0.22(0.06$ to 0.84$)$. Cows with BCS $=2.258 \mathrm{wk}$ previous to a severe lameness event were at reduced risk of lameness compared with the baseline
OR $(95 \%$ credible interval $)=0.16(0.03$ to 0.96$)]$. The HF:S cows were at significantly less risk of a first mild lameness event in second lactation and greater cows compared with the baseline category of LF:C [OR $(95 \%$ credible interval $)=0.07(0.01$ to 0.62$)]$. Other variables tested were not significant. Model fit was good.

\section{DISCUSSION}

Our work describes the analysis of a rich longitudinal data set, investigating risk factors for both repeated lameness events and first lifetime lameness event. Whereas previous papers have described low BCS as a risk factor for future lameness, this is the first study to identify fine thresholds of individual BCS as predic-

Table 6. Models 3a and 3b: final binomial models of risk of first lifetime lameness event in cows second lactation or greater, in the Crichton Royal research herd 2003 to 2011 with outcomes mildly lame (model 3a) and severely lame (model 3b)

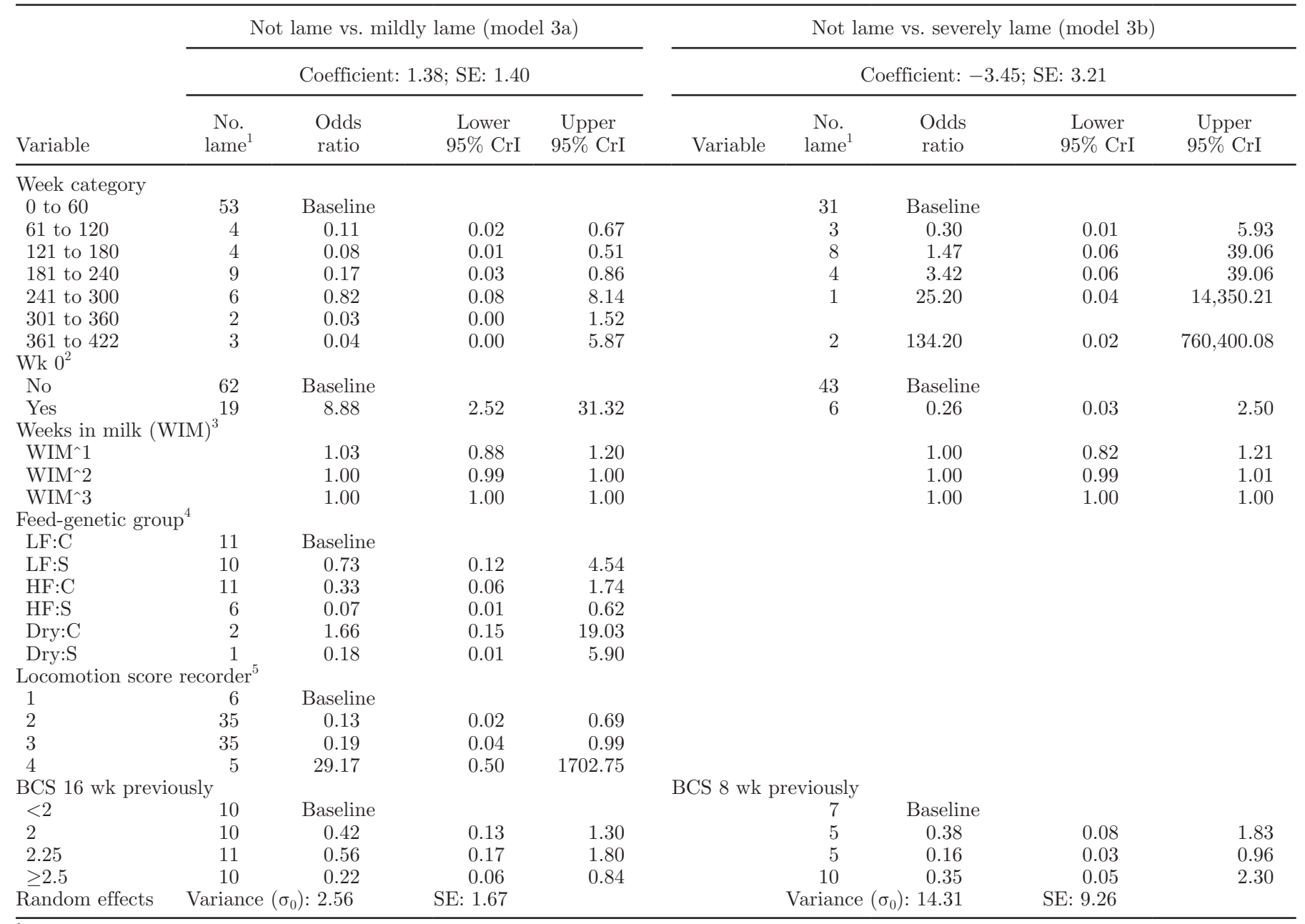

${ }^{1}$ Number of lameness events in each category. $\mathrm{CrI}=$ credible interval.

${ }^{2}$ Explanatory variable as a binary outcome for week $=0$.

${ }^{3}$ Explanatory variable weeks in milk (WIM) included as a polynomial to the power $3\left({ }^{\wedge} 3\right)$.

${ }^{4}$ Feed-genetic groups include low forage (LF), high forage (HF), control (C), and select (S). Dry refers to dry cows.

${ }^{5}$ Locomotion score recorder $=$ individual locomotion score/BCS observer identification. 
tors for mild and severe lameness. Cows with BCS $<2$ were at greatest risk of future mild or severe lameness, including first lifetime lameness events in second or higher lactation dairy cows, and long-term repeated lameness events in all parities. The results suggest that maintaining $\mathrm{BCS} \geq 2.5$ is optimal for reducing the risk of a lameness event. This study also provides evidence that low BW (independent of BCS), and age at first calving over 24 mo are important factors for long-term risk of repeated lameness events. Overall, model 1 explained 62 and $60 \%$ of the variability at cow level for mild and severe lameness, respectively, highlighting the importance of the variables investigated as risk factors, and which if managed, could have significant effects on controlling lameness on farm.

Body condition score has been associated with lameness related to claw horn lesions, possibly due to decreased thickness of the digital cushion and therefore reduced protective function (Bicalho et al., 2009; Green et al., 2014). The weekly locomotion scores over the 8-yr time period provided sufficient data and power in this study to allow analysis of individual BCS in increments of 0.25 , from 2 through to 3 (for multinomial analysis), only scores outside of this range needed to be merged. Based on the results of the current study, having controlled for stage of lactation, the minimum BCS to reduce the risk of mild or severe lameness was 2 but the risk decreased further as BCS increased. The results suggest that maintaining $\mathrm{BCS} \geq 2.5$ is optimal for reducing the risk of lameness. Although higher BCS were associated with a reduced risk of mild lameness in the current study, this needs to be balanced with maintaining an optimum BCS depending on stage of lactation, for the control of conditions such as metabolic disease and dystocia. Body condition score as a risk factor for lameness has been reported in several studies (Hoedemaker et al., 2009; Green et al., 2014; Lim et al., 2015). Green et al. (2014) reported that in a longitudinal study of 1,137 cows, those with BCS $\leq 2$ were more likely to be treated for lameness in the following 2 or 2 to 4 mo compared with cows with BCS $>2$. The results from that study support the findings of the current study, suggesting an association between low BCS and lameness that could be causal.

Notable in this analysis is that in the subset of cows with their first lifetime lameness event in the second lactation or higher, BCS had a significant effect 12 to $16 \mathrm{wk}$ previously for mild lameness and 8 to $12 \mathrm{wk}$ previously for severe lameness. Other lagged explanatory variables for BCS may also have had an effect, but due to low numbers in this subset of data and therefore reduced power, were not detectable. Body condition score did not, however, appear to have a significant effect on the first lifetime lameness event in first lacta- tion animals across the lagged explanatory variables for BCS tested, other than at 2 wk for mild lameness. The results support the hypothesis that BCS is an important risk factor for lameness, but that factors other than BCS may be important for risk of first lameness events in heifers. Explanations for this include the immature digital cushion at this age (Räber et al., 2006) or a different lameness etiology in heifers compared with later parity cows. Alternatively, it may be that in growing cattle (such as heifers) body condition scoring, which has been developed for mature animals, is less informative. Unfortunately, the cause of lameness was not defined in this data set and this study did not identify any risk factors that may be significant for first lameness events in heifers in this herd.

Periparturient BCS loss was also investigated as part of this study. Mobilization of lipid reserves in early lactation resulting in loss of body condition postpartum has been shown to contribute to increased risk of lameness (Hoedemaker et al., 2009). The results from this study support these previous findings; cows with loss in BCS 0 to 4 wk postcalving were more likely to be severely lame in the future. These results highlight the importance of avoiding BCS loss in early lactation and maintaining an appropriate BCS throughout a cow's lifetime as an aid to preventing lameness.

This is the first study to provide evidence for an association between BW and lameness, having adjusted for other factors including BCS. Norring et al. (2014) reported in a study of 70 dairy cows that severely lame cows had lower BW $(713 \pm 7 \mathrm{~kg}$ vs. $718 \pm 7 \mathrm{~kg}$ (BW \pm S.E) for lameness score 4 and 5 vs. 1 and 2, respectively). In that study, however, BW was not adjusted for BCS and therefore the reported difference in BW may have been influenced by the condition of the cows. The mechanisms by which BW influences the risk of lameness could be related to biomechanical (Capion et al., 2008), nutritional, or social factors. Based on results of the current study, possible explanations for the association between low BW and increased risk of lameness may be related to body condition and behavioral or social factors. Having controlled for BCS, it is possible that BW is an indicator of condition within each individual BCS category (for example, low BW score 2 cows may be thinner than high BW score 2 cows). Therefore, the association between lameness and low BW could have occurred because the risk of lameness may increase in cows that are lighter (and hence thinner), within each BCS category. Alternatively, behavioral and social function may explain the association between low BW and risk of lameness. Studies have shown that lameness is associated with lying times and lying times may affect recovery. Ito et al. (2010) found that severely lame cows spent $1.6 \mathrm{~h} / \mathrm{d}$ longer lying 
down than cows that were not severely lame on farms with deep bedded stalls, indicating a change in behavior that could aid recovery. Increased standing times or exposure to hard flooring surfaces have been shown to be risk factors for lameness and suggested to have a negative effect on recovery in lame cows (Galindo and Broom, 2000; Cook and Nordlund, 2009). Therefore, if lying times are reduced in lame cows, for example associated with lower social rank, this could potentially affect the risk of repeated lameness events. Galindo et al. (2000) investigated the relationships between social and individual behavior and incidence of lameness in 3 Holstein-Friesian dairy herds and demonstrated reduced lying times and reduced survival rate to lameness in low-ranking cows. It is possible, therefore, that in this study, low social ranking and associated stresses could have contributed to the increased risk of longterm repeated lameness observed in the $<550 \mathrm{~kg}$ of BW category cows compared with higher BW category cows. Further research is required to understand the interactions between BCS, BW, and lameness.

The current study provides evidence for the effect of age at first calving on the lifetime risk of lameness in dairy cows. Previous literature has only examined short-term effects within one lactation or effects on individual lesions. Sanders et al. (2009) reported that increased age at first calving decreased the hazard for thin sole-induced toe ulcers and white line disease, but increased the hazard for heel ulcers. Ettema and Santos (2004) demonstrated a greater incidence of lameness in the first lactation with older age at first calving $(\geq 25$ mo). Increased growth rates during the rearing period have been associated with younger age at first breeding and age at first calving (Brickell et al., 2009). Therefore, one hypothesis explaining the relationship between age at first calving and lifetime risk of repeat lameness is that an increased age at first calving may reflect animals that are less robust, with reduced ability to cope with their environment. As a consequence, these heifers may have had poorer growth rates, immune function, or disease status, which may then be reflected long-term with an increased susceptibility to lameness. Further research is required to investigate this hypothesis. Age at first calving has already been demonstrated to be an important factor influencing future health and productivity in dairy cows, with earlier age at first calving resulting in improved survivability, milk yield, and fertility (Bach, 2011; Cooke et al., 2013). The findings of the current study add weight to the evidence for earlier age at first calving in benefiting lifetime health and productivity of dairy cows.

Previous lameness events were significantly associated with the risk of current lameness. Green et al. (2014) and Reader et al. (2011) also reported this finding. One explanation is that treatments are not effective or long lasting or that the underlying risk, such as thin digital cushion associated with low BCS, is not removed by treatment. This association could also be explained by a lameness event resulting in damage that alters the structure or function of the claw, thereby increasing the susceptibility to future lameness, as suggested by Knott et al. (2007). These results indicate that managing herds to minimize the number of first cases of lameness in individual cows is an important factor in controlling lifetime risk of lameness.

Inclusion of feed-genetic groups within the model allowed the effect of genotype and environment on lameness to be accounted for alongside other risk factors. This is important in reflecting the multifactorial nature of lameness and allowed the effect of the cow factors described above to be distinguished from the environmental factor associated with duration of housing.

\section{CONCLUSIONS}

The findings from this study indicate that a BCS $<2$ is associated with the greatest risk of mild or severe lameness in dairy cows, and that the risk of lameness decreases with increased BCS. The results suggest that maintaining $\mathrm{BCS} \geq 2.5$ may be optimal for reducing the risk of lameness in dairy cows. These findings were relevant for long-term repeated lameness events and first time lameness events in second lactation and greater cows. This study also provides evidence for low BW and increased age at first calving, over 24 mo, being important risk factors for lifetime risk of repeated mild or severe lameness events in dairy cows. Other variables associated with increased risk of lameness included higher parity, loss in BCS 0 to 4 wk postcalving, higher milk yield 16 wk previously, feed-genetic group and time from occurrence of previous lameness events. The combination of risk factors explored in this study explained 62 and $60 \%$ of the variability for mild and severe lameness, respectively, highlighting their importance and where management interventions could be targeted to significantly affect reducing the risk of lameness in dairy herds.

\section{ACKNOWLEDGMENTS}

This work was supported by an Industrial CASE studentship. Funding from the Biotechnology and Biological Sciences Research Council (Swindon, UK) and Boehringer Ingelheim (Bracknell, UK) is gratefully acknowledged. We also acknowledge staff at the Scotland's Rural College's Dairy Research and Innovation 
Centre, specifically, Ainsley Bagnall, Maggie March, and Dave Roberts for access to and collection of the data.

\section{REFERENCES}

Amory, J. R., Z. E. Barker, J. L. Wright, S. A. Mason, R. W. Blowey, and L. E. Green. 2008. Associations between sole ulcer, white line disease and digital dermatitis and the milk yield of 1824 dairy cows on 30 dairy cow farms in England and Wales from February 2003-November 2004. Prev. Vet. Med. 83:381-391.

Archer, S., N. Bell, and J. Huxley. 2010a. Lameness in UK dairy cows: A review of the current status. In Practice 32:492-504.

Archer, S. C., M. J. Green, and J. N. Huxley. 2010b. Association between milk yield and serial locomotion score assessments in UK dairy cows. J. Dairy Sci. 93:4045-4053.

Bach, A. 2011. Associations between several aspects of heifer development and dairy cow survivability to second lactation. J. Dairy Sci. 94:1052-1057.

Bicalho, R. C., V. S. Machado, and L. S. Caixeta. 2009. Lameness in dairy cattle: A debilitating disease or a disease of debilitated cattle? A cross-sectional study of lameness prevalence and thickness of the digital cushion. J. Dairy Sci. 92:3175-3184.

Bicalho, R. C., L. D. Warnick, and C. L. Guard. 2008. Strategies to analyze milk losses caused by diseases with potential incidence throughout the lactation: A lameness example. J. Dairy Sci. 91:2653-2661.

Booth, C. J., L. D. Warnick, Y. T. Grohn, D. O. Maizon, C. L. Guard, and D. Janssen. 2004. Effect of lameness on culling in dairy cows. J. Dairy Sci. 87:4115-4122.

Brickell, J. S., N. Bourne, M. M. McGowan, and D. C. Wathes. 2009. Effect of growth and development during the rearing period on the subsequent fertility of nulliparous Holstein-Friesian heifers. Theriogenology 72:408-416.

Capion, N., S. M. Thamsborg, and C. Enevoldsen. 2008. Conformation of hind legs and lameness in Danish Holstein heifers. J. Dairy Sci. 91:2089-2097.

Chagunda, M. G. G., D. A. M. Römer, and D. J. Roberts. 2009. Effect of genotype and feeding regime on enteric methane, non-milk nitrogen and performance of dairy cows during the winter feeding period. Livest. Sci. 122:323-332.

Cook, N. B. 2003. Prevalence of lameness among dairy cattle in Wisconsin as a function of housing type and stall surface. J. Am. Vet. Med. Assoc. 223:1324-1328.

Cook, N. B., and K. V. Nordlund. 2009. The influence of the environment on dairy cow behavior, claw health and herd lameness dynamics. Vet. J. 179:360-369.

Cooke, J. S., Z. Cheng, N. E. Bourne, and D. C. Wathes. 2013. Association between growth rates, age at first calving and subsequent fertility, milk production and survival in Holstein-Friesian heifers. Open J. Anim. Sci. 3:1-12.

Dohoo, I., W. Martin, and H. Stryhn. 2003. Veterinary Epidemiologic Research. AVC Inc., Charlottetown, Canada.

Espejo, L. A., M. I. Endres, and J. A. Salfer. 2006. Prevalence of lameness in high-producing Holstein cows housed in freestall barns in Minnesota. J. Dairy Sci. 89:3052-3058.

Ettema, J. F., and J. E. P. Santos. 2004. Impact of age at calving on lactation, reproduction, health, and income in first-parity Holsteins on commercial farms. J. Dairy Sci. 87:2730-2742.

Galindo, F., and D. M. Broom. 2000. The relationships between social behaviour of dairy cows and the occurrence of lameness in three herds. Res. Vet. Sci. 69:75-79.

Galindo, F., D. M. Broom, and P. G. Jackson. 2000. A note on possible link between behaviour and the occurrence of lameness in dairy cows. Appl. Anim. Behav. Sci. 67:335-341.

Garbarino, E. J., J. Hernandez, J. K. Shearer, C. Risco, and W. W. Thatcher. 2004. Effect of lameness on ovarian activity in postpartum Holstein cows. J. Dairy Sci. 87:4123-4131.
Gelman, A., X. Meng, and H. Stern. 1996. Posterior predictive assessment of model fitness via realized discrepancies. Stat. Sin. 6:733-807.

Goldstein, H. 2003. Multilevel Statistics Models. 3rd ed. Arnold, London, UK.

Green, L. E., V. J. Hedges, Y. H. Schukken, R. W. Blowey, and A. J. Packington. 2002. The impact of clinical lameness on the milk yield of dairy cows. J. Dairy Sci. 85:2250-2256.

Green, L. E., J. N. Huxley, C. Banks, and M. J. Green. 2014. Temporal associations between low body condition, lameness and milk yield in a UK dairy herd. Prev. Vet. Med. 113:63-71.

Green, M. J., P. R. Burton, L. E. Green, Y. H. Schukken, A. J. Bradley, E. J. Peeler, and G. F. Medley. 2004. The use of Markov chain Monte Carlo for analysis of correlated binary data: Patterns of somatic cells in milk and the risk of clinical mastitis in dairy cows. Prev. Vet. Med. 64:157-174.

Herrero, M., and P. K. Thornton. 2013. Livestock and global change: Emerging issues for sustainable food systems. Proc. Natl. Acad. Sci. USA 110:20878-20881.

Hoedemaker, M., D. Prange, and Y. Gundelach. 2009. Body condition change ante- and postpartum, health and reproductive performance in German Holstein cows. Reprod. Domest. Anim. 44:167-173.

Hosmer, D. W., and S. Lemeshow. 1989. Applied Logistic Regression. Wiley, New York, NY.

Huxley, J. N. 2012. Lameness in cattle: An ongoing concern. Vet. J. 193:610-611.

Ito, K., M. A. von Keyserlingk, S. J. Leblanc, and D. M. Weary. 2010. Lying behavior as an indicator of lameness in dairy cows. J. Dairy Sci. 93:3553-3560.

Knott, L., J. F. Tarlton, H. Craft, and A. J. F. Webster. 2007. Effects of housing, parturition and diet change on the biochemistry and biomechanics of the support structures of the hoof of dairy heifers. Vet. J. 174:277-287.

Lim, P. Y., J. N. Huxley, J. A. Willshire, M. J. Green, A. R. Othman, and J. Kaler. 2015. Unravelling the association between lameness and body condition score in dairy cattle using a multistate modelling approach. Prev. Vet. Med. 118:370-377.

Manson, F. J., and J. D. Leaver. 1988. The influence of concentrate amount on locomotion and clinical lameness in dairy cattle. Anim. Prod. 47:185-190.

Mulvany, P. M. 1977. A body condition scoring technique for use with British Friesian cows. Anim. Prod. 24:157-158.

Norring, M., J. Häggman, H. Simojoki, P. Tamminen, C. Winckler, and M. Pastell. 2014. Short communication: Lameness impairs feeding behavior of dairy cows. J. Dairy Sci. 97:4317-4321.

Pryce, J. E., B. L. Nielsen, R. F. Veerkamp, and G. Simm. 1999. Genotype and feeding system effects and interactions for health and fertility traits in dairy cattle. Livest. Prod. Sci. 57:193-201.

Rabash, J., C. Charlton, W. J. Browne, M. Healy, and B. Cameron. 2009. Mlwin version 2.1. Centre for Multilevel Modelling, University of Bristol.

Räber, M., M. R. L. Scheeder, P. Ossent, C. J. Lischer, and H. Geyer. 2006. The content and composition of lipids in the digital cushion of the bovine claw with respect to age and location-A preliminary report. Vet. J. 172:173-177.

Reader, J. D., M. J. Green, J. Kaler, S. A. Mason, and L. E. Green. 2011. Effect of mobility score on milk yield and activity in dairy cattle. J. Dairy Sci. 94:5045-5052.

Sanders, A. H., J. K. Shearer, and A. De Vries. 2009. Seasonal incidence of lameness and risk factors associated with thin soles, white line disease, ulcers, and sole punctures in dairy cattle. J. Dairy Sci. 92:3165-3174.

Whay, H. R., D. C. J. Main, L. E. Green, and A. J. F. Webster. 2003. Assessment of the welfare of dairy cattle using animal-based measurements: Direct observations and investigation of farm records. Vet. Rec. 153:197-202. 